\title{
NY LITTERATUR
}

Johannes Andenas: Norsk straffeprosess 3. utg. Universitetsforlaget, Oslo 2000. 2 bd. ISBN 82-00-45414-2.

Kauko Aromaa: Crime risk in Finland 2000: finnish results of the 2000 sweep of the international crime victims survey. National Research Institute of Legal Policy, Helsinki 2000. 36 s. (Research Communications ; 50) ISBN 951-704-253-1

Petter Asp: Straffansvar vid brottsprovokation. Norstedts Juridik, Stockholm 2001. 352 s. ISBN 91-39-00683-2

Betankning nr. 1396 om Straffelovens $\$ 289 \mathrm{mv}$. - berigelseskriminalitet rettet mod offentlige midler. Delbetænkning V afgivet af Justitsministeriets udvalg om økonomisk kriminalitet og datakriminalitet. København 2001. ISBN 87-601-8919-3. 157 s. DKK 75. Publikationen kan hentes på Justitsministeriets hjemmeside http://www.jm.dk/publikationer/bet1396

Betankning nr. 1401 om Reform af den civile retspleje I. Afgivet af Retsplejerådet. København 2001. ISBN 87-601-8980-0. 701 s. DKK 150. Publikationen kan hentes på Justitsministeriets hjemmeside www.jm.dk/publikationer/bet1401

Mike Brogden: Geronticide - Killing the Elderly. Jessica Kingsley Publishers, London 2001. ISBN 1-85302-709-X. 221 s. £15.95

Philippe de Bruycker (ed): Regulations of Illegal Immigrants in the European Union. BRUYLANT, Bruxelles 2000. ISBN 2-8027-1389-2. $420 \mathrm{~s}$.

Brottsförebyggande rådet: Efter muck: från anstalt till livet $i$ frihet. BRÅ-rapport 2001:2. BRA/Fritze, Stockholm 2001. ISBN 91-38-31771-0. $50 \mathrm{~s}$.

Brottsförebyggande rådet: White-collar crime research old views and future potentials -

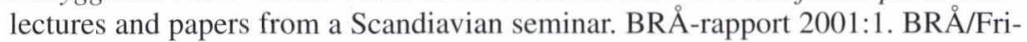
tze, Stockholm 2001. ISBN 91-38-31720-6. 193 s.

Tore Bråthen \& Ole Gjems-Onstad (red.): Moderne forretningsjus. Gyldendal Akademisk, Oslo 2001. ISBN 82-05-28110-6. 171 s. NOK 265.

David Bunnage, Ole Gregersen, Eigil Boll Hansen, Nanna Meilbak \& Merete Platz: Kvalitet $i$ aldreplejen. SFI-publikation 01:3. Socialforskningsinstituttet, København 2001. ISBN 87-7487-657-0. $184 \mathrm{~s}$.

David Canter \& Laurence Alison (eds.): Profiling Property Crimes. Ashgate, Dartmouth 2000. ISBN 1-84014-787-3. 328 s. £19.50

Nils Christie: Kriminalitetskontrol som industri. På vej mod Gulag, vestlig stil. Anden reviderede udgave. Hans Reitzels Forlag, København 2001. ISBN 87-412-26135. 237 s. DKK 268.

Magnus Dahlberg \& Evert Vedung: Demokrati och brukarutvärdering. Studentlitteratur, Lund 2001. ISBN 91-44-01519-4. $130 \mathrm{~s}$.

Maria Danielsson: Nordisk statistik för kriminalvården i Danmark, Finland, Norge och Sverige 1995-1999. Kriminalvårdsstyrelsen, Norrköping 2000. $37 \mathrm{~s}$.

Albin Eser \& Jörg Arnold (Hrsg.): Strafrecht in Reaktion auf Systemunrecht. Bind 2 Deutschland. edition iuscrim, Freiburg 2000. ISBN 3-86113-937-5. 662 s. DM 68.

Mette Groes: Hustruvold. Socialrådgiverens arbejdsmetoder: Gyldendal Uddannelse, København 2001. ISBN 87-00-48506-3. 144 s. DKK 148. 
Walter Gropp \& Barbara Huber (hrsg.): Rechtliche Initiativen gegen organisierte Kriminalität. edition iuscrim, Freiburg im Breisgau 2001. ISBN 3-86113-935-9. $991 \mathrm{~s}$. DM 95.

Rasmus Heugh Wandall: Disciplinarregler, disciplinering og legitimering - anvendte disciplinære regler og sanktioner i dansker arresthuse. Jurist- og Økonomforbundets Forlag, København 2001. ISBN 87-574-0368-6. 132 s. DKK 185

Ronald M. Holmes \& Stephen T. Holmes: Murder in America. Sage Publication, London 2001 ISBN 0-7619-2092-7. 190 s. £19.99

Vera Holm $\phi y$ \& Peter Lфdrup: Ekteskapsloven - og enkelte andre lover med kommentarer. Gyldendal Akademisk, Oslo 2001. ISBN 82-417-1148-4. 774 s. NOK 850.

Institutt for kriminologi: Årsrapport 2000. Universitetet i Oslo/ Det Juridiske Fakultet, Oslo 2001. $141 \mathrm{~s}$.

International Criminal Tribunal for Rwanda. Reports of Orders, Decisions and Jugdements 1995-1997. BRUYLANT, Bruxelles 2000. ISBN 2-8027-1367-1. $834 \mathrm{~s}$.

Staffan Janson: Barn och misshandel. SOU-rapport 2001:18. Statens Offentliga Utredninger, Stockholm 2001. ISBN 91-38-21411-3. $100 \mathrm{~s}$.

Jørgen Jepsen: Narkotikakrigens ofre. Afskedsforelasning. Center for Rusmiddelforskning, Århus 2001. 24 s.

Asbjørn Kjønstad \& Aslak Syse: Velferdsrett I. Gyldendal Akademisk, Oslo 2001. ISBN 82-415-1147-6. $494 \mathrm{~s}$.

Kommenteret retsplejelov bd. 1, 2 og 3. Jurist og Økonomforbundets Forlag, København 2000. ISBN 87-574-6855-9

Kriminalvården: Kriminalvårdens Budgetunderlag 2002. Kriminalvårdstyrelsen, Norrköping 2001. $53 \mathrm{~s}$.

Kriminalvården: Kriminalvårdens Redovisning om Aterfall 1999. Kriminalvårdstyrelsen, Norrköping 2001. 83 s.

Kriminalvården: Kriminalvårdens Årsredovisning 2000. Kriminalvårdstyrelsen, Norrköping 2001. $57 \mathrm{~s}$.

Per Arne Larsen: Arbejdsmiljøloven. 2. reviderede utgave. Gyldendal Akademisk/Tiden Norsk Forlag, Oslo 2001. ISBN 82-10-04648-9. 640 s.

Paul Larsson: Hvitere enn hvitsnippkriminalitet - en studie av reguleringen av kriminalitet i verdipapirmarkedet. Norges forskningsråd, Oslo 2001. ISBN 82-12-01557-2. $95 \mathrm{~s}$.

Gitte Lindemann \& Ole Gregersen: Benchmarking på fortidspensionsområdet - virker Den Sociale Ankestyrelses praksiskoodinering? Socialforskningsinstituttet 01:2. Socialforskningsinstituttet, København 2001. ISBN 87-7487-654-6.60 s. DKK 50.

Thomas Mathiesen: Sidste ord er ikke sagt: Schengen og globaliseringen af kontrol. København : Forlaget Politisk Revy, København 2001. ISBN 87-7378-209-2. 112 s.

John Muncie \& Eugene McLaughlin (eds.): The Problem of Crime. SAGE Publications, London 2001. ISBN 0-7619-6971-3. 342 s. £17.99

Eugene McLaughlin \& John Muncie (eds.): Controlling Crime. SAGE Publications, London 2001. ISBN 0-7619-6973-X. 362 s. £17.99

Nordisk arbejdsgruppe om ungdomskriminalitet: Ungdomskriminalitet $i$ Norden. Nord 2000:30. Nordisk Ministerråd, København 2000. ISBN 92-893-0565-7. 149 s. 
Politihistorisk Selskab: Årsskrift. Politihistorisk Selskab, København. ISSN 0107-3893. Rapport fra NSfK's 19. kontaktseminar, Göteborg, Sverige 2000 om "Praktikens" behov av kriminologisk forskning och utbilding. Udgivet af Nordisk Samarbejdsråd for Kriminologi, København 2000, 67 s. ISBN 87-987103-1-1

Christoph Safferling: Towards an International Criminal Procedure. Oxford University Press, Oxford 2001. ISBN 0-19-924350-6. 395 s. £60.00

Aslak Syse: Patientrettighetsloven med kommentarer. Gyldendal Akademisk, Oslo 2001. ISBN 82-417-1151-4. $323 \mathrm{~s}$.

Statens offentliga utredningar: Children in Homosexual Families. Summary. SOU-rapport 2001:10. SOU/Fritzes, Stockholm 2001. ISBN 91-38-21429-6. $23 \mathrm{~s}$.

Statens offentliga utredningar: Domstolarnas register och person-uppgiftslagen. SOUrapport 2001:32. SOU/Fritzes, Stockholm 2001. ISBN 91-38-21439-3. 146 s.

Statens offentliga utredningar: Sexualbrotten. Ett ökat skydd för den sexuella integriteten och angränsande frågor. SOU-rapport 2001:14. SOU/Fritzes, Stockholm 2001. ISBN 91-38-21407-5. $697 \mathrm{~s}$.

Statens offentliga utredningar: Sjöfylleri. SOU-rapport 2001:30. SOU/Fritzes, Stockholm 2001. ISBN 91-38-21437-7. $184 \mathrm{~s}$.

Statens offentliga utredningar: Yttrandefrihetsgrundlagen och Internet. SOU-rapport 2001:28. SOU/Fritzes, Stockholm 2001. ISBN 91-38-21435-0. 611 s.

Sundhedsstyrelsen: Narkotikasituationen i Danmark 1999 - årsrapport til det europæiske center for overvågning af narkotika og narkotikamisbrug, EMCCDA. Sundhedsstyrelsen, København 2000. 24 s.

Kerstin Svensson: I stället för fängelse? En studie av vårdande makt, straff och socialt arbete i frivård. Socialhögskolan/Lunds Universitet, Lund 2001. ISBN 91-8960400-8. $277 \mathrm{~s}$.

Charles Tilly: Beständig ojämlikhet. Arkiv, Lund 2000. ISBN 91-7924-135-2. 272 s.

Torbjörn Tännsjö: Coercive Care. The ethics of choice in health and medicine. Routledge, London 1999. ISBN 0-415-20849-1. $163 \mathrm{~s}$.

Brandan C. Welsh, David P. Farrington \& Lawrence W. Sherman: Costs and Benefits of Preventing Crime. Westwiew Press, Boulder, Colorado 2001. ISBN 0-8133-97804. $289 \mathrm{~s}$.

Geir Woxholth: Avtaleinngåelse, ugyldighet og tolkning. Gyldendal Akademisk, Oslo 2001. ISBN 82-05-28747-3. $498 \mathrm{~s}$. 